\title{
An approach to quantify value provided by an engineered asset according to the ISO 5500x series of standards
}

\author{
Vicente Gonzalez-Prida ${ }^{1}$, Antonio Guillén², Juan Gómez ${ }^{3}$, Adolfo Crespo ${ }^{4}$, \\ Antonio de la Fuente ${ }^{5}$
}

\begin{abstract}
The purpose of any asset is to provide value to the organization and its stakeholders. In Asset Management, the concept of value encompasses quantitative and qualitative, as well as tangible and intangible benefits that assets may provide to an organization. The definitions of asset and value are not only closely linked but also complementary. An "asset" provides the means for the realisation of "value" thus the management of an asset is strategic and has to be linked to an organization's value norms. This paper extrapolates from the definitions in ISO 5500x series of standards to describe a generic approach for quantifying the value provided by engineered assets deployed by a business organisation.
\end{abstract}

\footnotetext{
${ }^{1}$ Vicente Gonzalez-Prida. $(\square)$

Department of Industrial Management, University of Seville, Spain. e-mail: vicente.gonzalezprida@gdels.com

${ }^{2}$ Antonio Guillén.

Department of Industrial Management, University of Seville, Spain. email: ajguillen@us.es

${ }^{3}$ Juan Gómez.

Department of Industrial Management, University of Seville, Spain. email: juan.gomez@iies.es

${ }^{4}$ Adolfo Crespo.

Department of Industrial Management, University of Seville, Spain. email: adolfo@etsi.us.es

5 Antonio de la Fuente

Department of Industrial Management, University of Seville, Spain. e-mail: antoniodela84@gmail.com
}

$12^{\text {th }}$ World Congress on Engineering Asset Management \& $13^{\text {th }}$ International Conference on Vibration Engineering and Technology of Machinery 2-4 August 2017, Brisbane, Australia 
2 V. Gonzalez-Prida, A. Guillén, J. F. Gómez, A. Crespo, A. de la Fuente. - An approach to quantify value provided by an engineered asset according to the ISO 5500x series of standards.

\section{Introduction}

The purpose of any asset is to provide value to the organization and its stakeholders (ISO, 2015a). In Asset Management (AM), the concept of value considers all those aspects (obtained or expected to be obtained from an asset) that provide any kind of benefit (expressed in specific terms) to the organization (Sola et Al., 2015). The definition of both, asset and value, are complementary to each other. Indeed, asset and value are two concepts closely involved where there is no sense one without the other. In few words, the "asset" is the tool or the instrument for materializing the "value" expected by the company, and this fact encompasses the company strategic objectives. Each asset must be defined and managed based on its link to the concept of the organization's own value (Sola et Al., 2015). The definition of value for each company / organization, must serve to determine and describe, accurately, the asset portfolio of each organization, answering the questions of what those assets are and how they contribute to precisely achieve or conserve this value (IAM, 2010).

Asset management should be founded in the value control. But many times the value concept is not actively integrated in the management tools, and only financial/economic variables -only limited to cost most cases- are used for the control and decision-making. The idea of value is present in these processes, of course, but not in a formal way neither including objective evaluation methods. The challenge here is to design a methodology that allows the quantification of such a value and its effective use in asset management. Even ISO 55000 , where the capital role of value has definitively been put on the table, does not address the value measurement. The effective control of value, which needs the introduction of value assessment methods, can promote great benefits for the overall organization management. (Lopez \& Crespo, 2010) throughout this document, a generic approach to quantify assets value is presented, according and aligned to the concept defined in the standards ISO 55000 (ISO, 2015a; ISO, 2015b; ISO, 2015c)

In this context, it is needed a deep revision about the current use of value as key concept in AM including, or starting from, a philosophical discussion about the definition of value concept. But this goes great beyond the scope and the extension intended by this paper. Nevertheless, in order to promote the discussion some references have been included here that can be consulted as a starting point: Cronin et al. (2000) includes a review of value, quality and satisfaction concepts in services marketing literature; Harrison et al. (2013) offer the stakeholder perspective on value, draw attention to those factors that are most closely associated with building more value for stakeholders; Heitz et al. (2016) present a formal model for decision making in asset management, based on the general concepts of ISO 55000, in particular the notion of value realization; Hofmann et al. (2016) present a use case of value-based performance measurement concept in supply chains, Campbell et al. (2016) present a general framework for Asset Management and 
V. Gonzalez-Prida, A. Guillén, J. F. Gómez, A. Crespo, A. de la Fuente. - An approach to quantify value provided by an engineered asset according to the ISO 5500x series of standards.

maintenance where interesting value-risk references can be found; Kaplan \& Norton, (1992) with the Balance Score Card they developed, the fact, a practical method to aboard the inclusion of approaches different from economical aspect in management of any kind of organization, and in this sense, this is an evident precursor of value approach; Allee, V. (2008) gives a good approach to value analysis for intangible assets management. Among these references, other fields appear too in addition of engineering and AM as economics market, customer studies, marketing and intellectual capital management etc. All these areas present more mature visions about value modelling and its utility for management. These fields treat this issue from different perspectives that, somehow, can help to the engineer and asset manager to build an own vision that contributes to the evolution of AM.

The paper is organized as follow: section 2 introduces the approach to the value concept in an organization that summarizes the vision of this paper to the value definition. This section includes two subsections: in 2.1 it is discussed the different between a negative assessment of value, or "loss of value", and positive assessment of value, or "gain of value"; 2.2 gives examples to understand the value assessments approaches. Finally, conclusions are summarized in section 3.

\section{The Value Concept in an Organization}

Since the publication of ISO 5500x, the term Value has become the buzz word in Asset Management (Crespo \& Sola 2016). However, in the literature review cannot be found yet many contributions dealing specifically with the value concept for an organization. In general terms, value is intuitively easy to understand. However, its objective definition is not easy to delimit, moreover, when the goal is to establish methods of measurement that allow the decision-making to be made in terms of value (Amadi-Echendu et al., 2010). Basically, each organization has to define its own value concept. In other words, the organization value concept $(\mathrm{OCV})$ as a specific element must include and describe all the relevant components of the overall value view of the organization. A property of value is that, it is created during the operation of the asset portfolio. This means: Value is generated over time. Thus, value is defined more precisely as a value stream or value creation rate $\mathrm{v}(\mathrm{t})$. For example, a production system that produces items with a specific production rate can be seen as generating value during its operation, and this value might be expressed in units "\$ per time" (Heitz, Goren, \& Sigrist, 2016). Another property of value is that one that can typically be defined just at a portfolio level, not on the single asset level. In most cases, a single asset as such has no value at all

Consider, for example, an electrical transformer of an electricity supply network. Taken alone, this transformer has no value at all. It only creates value as a part of a network, i.e. within an asset portfolio. Thus, it is quite natural (and often required) to define value creation on the portfolio level (Heitz et al., 2016). The 
4 V. Gonzalez-Prida, A. Guillén, J. F. Gómez, A. Crespo, A. de la Fuente. - An approach to quantify value provided by an engineered asset according to the ISO 5500x series of standards.

value is implicitly treated in the definition of the Organizational Objectives, then in the Asset Management Policy (AMP) and, finally, in the Asset Management Objectives (AMO) within the SAMP (ISO 2015a). We say implicitly because although relevant information about the value is presented in these descriptions there is no more mention to value once the objectives are introduced. So the link with value assessment or control is indirect through Objectives (OO and AMO). With the generalization of AM (not only limited only to ISO 55000) and supporting on new information technologies the effective assessment of value is now possible. Value Components (VCs): The first step is the determination of value components. VCs are those general aspects that can be included in the value definition. In other words, the value can be expressed through its components. These components are usually employed in the Objectives description. VCs can be: social impact, other stakeholders' impact, safety, environmental, operation/capability, profits, etc. Value components can include aspects which are very difficult to evaluate in monetary terms. Most of the cases, almost any value aspect can be translated to monetary terms. But many cases the models to do this are very complicated and they are not accurate at all, presenting a great level of uncertainty. Two aspects are fundamental in the value of industrial systems.

For example, in the case of a railroad system (UIC, 2016):

(i) The social or public service related to the system in which it is integrated. Aspects, such as utilization, assured service times, etc. have a direct impact on the life of cities. This impact is not only on its inhabitants but on the attraction of visits and investments. Public transport is one of the main image references in any city;

(ii) The user safety: it is a key aspect in the exploitation of any means of transport. In the case of railroad systems, safety is one of their main advantages in front of any other urban transportation.

Value Factors (VFs): in this second step, we try to translate the VC to specific term that can be used by management approach. Therefore, VFs are defined from VCs, but:

- A VF has a very accurate definition.

- A VF can be measure using specific indicators.

- The measure can be quantitative or semi-quantitative.

- A VF should be additive and scalable.

- $\quad$ One VF can include references to one or more VCs (i.e. we can define a unique VF for Security and Safety).

- $\quad$ Each VF has a relative weigh for the Value composition.

- $\quad$ VF is related to global optimization point.

Finally, the management objects are the assets. We are going to measure and act over the assets to get value from them. Asset portfolio definition, once value 
V. Gonzalez-Prida, A. Guillén, J. F. Gómez, A. Crespo, A. de la Fuente. - An approach to quantify value provided by an engineered asset according to the ISO 5500x series of standards.

has been described through $\mathrm{VC}$ and VF is part of OCV. It is also necessary to define how each asset contributes to gain or to loss of value.

Summarizing, the OCV include:

1. Defining the VCs (concept of value within the whole system operation). Determining the key aspects of the organization / business strategy and how to express them in terms of value.

2. Designing tools to measure and control the asset value. For this purpose, Value Factors (VF) will be used. The VF allow to express in measurable terms, all those aspects that constitute the value for a given business / organization.

3. Defining assets of the whole system. The definition of value determines "for what" the organization needs or will use the assets. Only on that basis, it is possible to precisely define the assets of an organization. It translates (at a practical level), the structure and tasks that include the own definition and description of the established value criteria.

\subsection{Positive and Negative Asset Value Assessment (AVA)}

Establishing the OCV, the own concept of value according to the company or organization point of view, it is possible to define methodologies to measure the value. The measures are always related to the asset. The asset is the element that provides value. These methodologies should be preferably objective and be included in the decision-making processes of the company. In general terms, processes can be classified as a strategic, tactical and operational level. This vision is complemented by the time horizon considered in the decision making. Consequently, methodologies for the evaluation of value according to the asset impact over the whole system process and goals will be fundamental in any asset management model. In our approach, value is composed as commented by a series of factors. These VFs can be used in two types of methods:

- $\quad$ Positive Control: Assessing the contribution or gain during the asset useful live. It can be the contributed value until a specific moment or the expected gain until the end of the useful life.

- Negative Control: Assessing the value reduction or loss due to events that have caused a reduction of the value or it is foreseen they will cause an expected loss of value. Failures fall into this category. Each potential asset failure has, as a risk consequence, a potential loss of value. This can range from low impact to catastrophic.

The suitable application of these methods will depend on how the VF is defined. The positive contribution, for instance, may be calculated considering the contribution of asset availability in reference to the whole system availability, in order to obtain an expected production or gain. The negative contribution may be calculated from criticality assessment of the specific asset. Both, positive and neg- 
6 V. Gonzalez-Prida, A. Guillén, J. F. Gómez, A. Crespo, A. de la Fuente. - An approach to quantify value provided by an engineered asset according to the ISO 5500x series of standards.

ative terms, will depend on the nature of the asset itself, but also, on the asset location throughout the whole system configuration.

\subsection{Asset Value Assessment method example}

As commented, there is no consensus for the definition of the value provided by a physical asset. One option proposed here is to define factors similarly to those used in the criticality analysis. Criticality analysis is basically as methodology that allows hierarchizing systems, facilities and equipment (assets). Fig 1 represents the results of real Criticality Analysis of industrial plant in the Oil \& Gas sector.

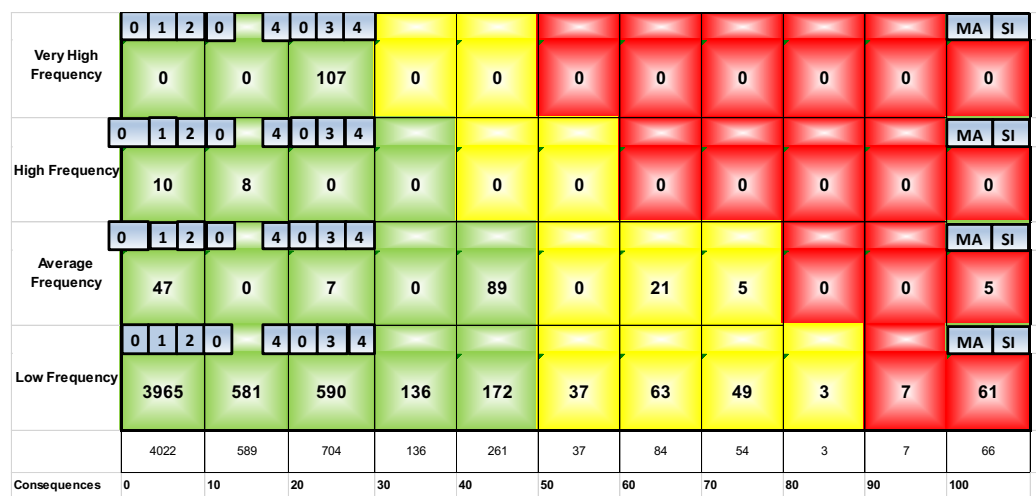

Fig. 1 Risk \& Value based Asset Criticality Analysis matrix

Usually, it is measured similarly to risk, taking into account the frequency of a failure event, and the consequences that can be generated when that failure occurs. Failure frequency is usually a measurable aspect (or there are databases or other reference sources). On the other hand, consequences refer to the effects in terms of costs (operating, environmental, maintenance, etc. costs). It often requires a consensus among experts. The criteria to be agreed would be, for example: Safety (are dangerous working conditions for people? are there safety measures?); Environment (is the failure dangerous for the environment? are there contingency measures?); Production (does the failure totally paralyze the plant? if not, how soon is it operational again?); O\&M Costs (how much does it cost to recommission the equipment?). Mathematically, we could formulate the concept of criticality as:

\section{Risk $=$ Likelihood $x$ Consequence}

Therefore, criticality can be assessed through the estimation of loss of value when a failure event occurs. Consequences can be measures through a Value Fac- 
V. Gonzalez-Prida, A. Guillén, J. F. Gómez, A. Crespo, A. de la Fuente. - An approach to quantify value provided by an engineered asset according to the ISO 5500x series of standards.

tors accurate definition, independently from costs aspects. Moreover, it is important to consider the "value" interpretation given by stakeholders or interested parties and, in the some specific cases, the value observed by the user as an intangible social benefit.

As an illustrative example (and not intended to be exhaustive), the following figure (Fig. 2) shows graphically a value quantification related to an industrial case from the point of view of the safety dimension. This a priori intangible dimension is forced to be quantified as an accumulation of days without accidents. The theoretical cumulative value in this case represents the total of days operating the system throughout the whole life cycle (35 years in this example). The Total Life Cycle Value (LCV) would represent the realistic behaviour of the physical asset throughout its useful life. No accidents would mean the achievement of the total maximal value for the asset, observed from the point of view of the safety dimension.

Future research works may be focused on the development of similar examples, although adapted to the particular casuistry of the diverse scenarios under study and different dimensions for the concept of value. Particularly, extensions to this contribution may deal with the development of specific mathematical methods that allow calculating the value perception of an organization in reference to a specific asset, being such value translated into numerical quantities. 
8 V. Gonzalez-Prida, A. Guillén, J. F. Gómez, A. Crespo, A. de la Fuente. - An approach to quantify value provided by an engineered asset according to the ISO 5500x series of standards.

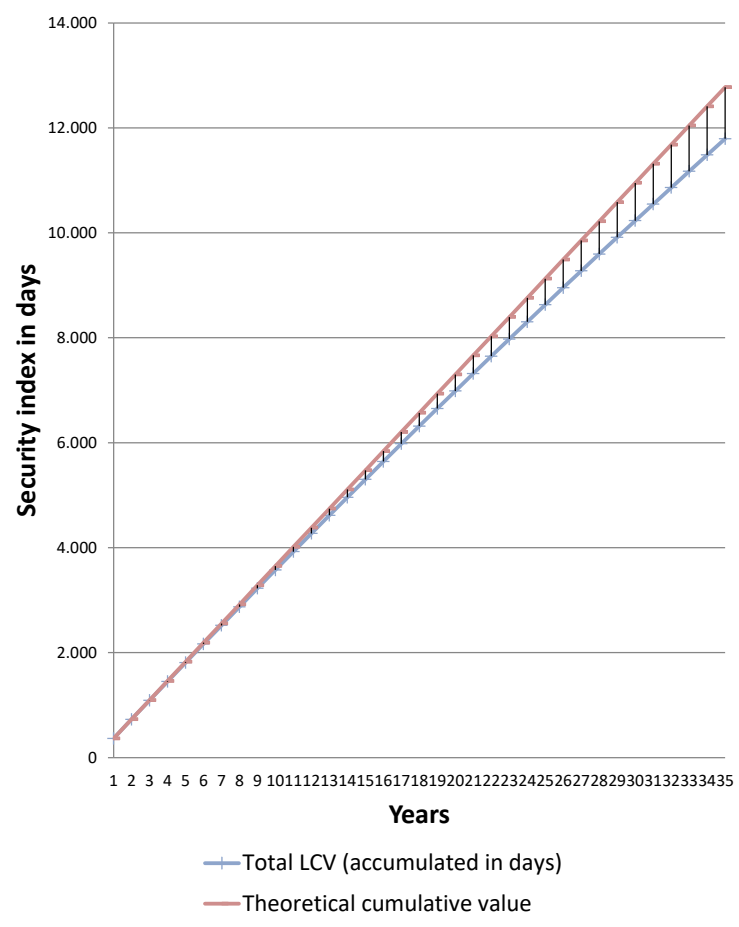

Fig. 2 Example of Life Cycle Value assessment

\section{Conclusions}

As a conclusion, it should be emphasized that physical assets have usually been managed by the departments or areas dedicated to maintenance, being in charge of the control of the installations as well as the repair and revision work, in order to assure the regular operation of the service and/or production, as well as preserving the appropriate state of the infrastructures. However, this activity has evolved in order to reach the current concept of AM by which it is understood as: "those coordinated activities in an organization, intended to obtain value from its assets" (Sola \& Crespo, 2016). To this aim, what has been proposed in this document is an efficient approach to face the changing challenges in the industrial sector. Under these assumptions, the benefits of implementing an AM model, with an integrated approach in order to achieve value throughout the asset life cycle, are solidly proven in industry, improving service quality through its contribution to safety, human health and environmental protection. 
V. Gonzalez-Prida, A. Guillén, J. F. Gómez, A. Crespo, A. de la Fuente. - An approach to quantify value provided by an engineered asset according to the ISO 5500x series of standards.

\section{Acknowledgment}

This research work was performed within the context of Sustain Owner ('Sustainable Design and Management of Industrial Assets through Total Value and Cost of Ownership'), a project sponsored by the EU Framework Program Horizon 2020, MSCA-RISE-2014: Marie Skłodowska-Curie Research and Innovation Staff Exchange (RISE) (grant agreement number 645733 - Sustain-Owner - H2020MSCA-RISE-2014); and the project "DESARROLLO DE PROCESOS AVANZADOS DE OPERACION Y MANTENIMIENTO SOBRE SISTEMAS CIBERO FISICOS (CPS) EN EL AMBITO DE LA INDUSTRIA 4.0", Ministerio de Economía y Competitividad del Gobierno de España, Programa Estatal de I+D+i Orientado a los Retos de la Sociedad.DPI2015-70842-R, financed bycon FEDER (Fondo Europeo de Desarrollo Regional)

\section{References}

Allee, V. (2008). Value network analysis and value conversion of tangible and intangible assets. Journal of intellectual capital, 9(1), 5-24.

Amadi-Echendu, J. E., Willett, R., Brown, K., Hope, T., Lee, J., Mathew, J. \& Yang, B. S. (2010). What is engineering asset management?. In Definitions, concepts and scope of engineering asset management (pp. 3-16). Springer London.

Campbell J.D, Jardine A.K.S , McGlynn J., 2016. Asset Management Excellence: Optimizing Equipment Life-Cycle Decisions. CRC Press.

Cronin, J. J., Brady, M. K., \& Hult, G. T. M. (2000). Assessing the effects of quality, value, and customer satisfaction on consumer behavioral intentions in service environments. Journal of retailing, 76(2), 193-218.

Harrison, J. S., \& Wicks, A. C. (2013). Stakeholder theory, value, and firm performance. Business ethics quarterly, 23(01), 97-124.

Heitz, C., Goren, L., \& Sigrist, J. (2016). Decision Making in Asset Management: Optimal allocation of Resources for Maximizing Value Realization. Proceedings of the 10th World Congress on Engineering Asset Management. https://doi.org/10.1007/978-3-319-27064-7_25

Hofmann, E., \& Locker, A. (2009). Value-based performance measurement in supply chains: a case study from the packaging industry. Production Planning and Control, 20(1), 68-81. 
10 V. Gonzalez-Prida, A. Guillén, J. F. Gómez, A. Crespo, A. de la Fuente. - An approach to quantify value provided by an engineered asset according to the ISO 5500x series of standards.

IAM (2011). Asset Management - An Anatomy. Institute of Asset Management, UK

ISO, 2015a, ISO 55000:2015. Asset management - Overview, principles and terminology.

ISO, 2015b, ISO 55001:2015. Asset management - Management systems - Requirements,

ISO, 2015c, ISO 55002:2015. Asset management - Management systems Guidelines for the application of UNE-ISO 55001:2015

ISO, 2006, ISO 14224:2006 - Petroleum, petrochemical and natural gas industries -- Collection and exchange of reliability and maintenance data for equipment.

Kaplan, R. S., \& Norton, D. P. 1992. The balanced scorecard: Measures that drive performance. Harvard Business Review, 70(1) (January/February): 71-79.

Sola A., Crespo A., 2016. Asset management principles and frameworks. Aenor. Madrid.

López M., Crespo A. (2010). Modelling a Maintenance Management Framework Based on PAS 55 Standard. Quality and Reliability Engineering International. DOI: $10.1002 /$ qre.1168

PAS 55 (2008). Gestión de Activos Parte 1. British Standard Institute, ISBN: 978-0-9563934-0-1 505PAS 55 (2008). Gestión de Activos Parte 2. British Standard Institute, ISBN: 978-0-9563934-2-5 507

Sola, A.; Crespo, A.; Guillen, A. (2015). Bases para la mejora de la gestión de activos en las organizaciones. Industria Química

UIC, 2016. UIC Railway Application Guide - Practical Implementation of Asset Management through ISO 55001. UIC 